\title{
Masculinidades em diálogo: Produção de sentido a partir de marcadores sociais da diferença
}

\author{
Icaro Bonamigo Gaspodini* \\ Ronaldo Pires Canabarro* \\ Cláudia Mara Bosetto Cenci** \\ Clándia Maria Perrone ${ }^{* * *}$
}

\begin{abstract}
Resumo
Neste estudo, investigou-se a produção de sentidos subjetivos em relação à identidade de gênero masculina. Quatro homens cisgêneros (26, 31, 32 e 37 anos), residentes e nascidos em cidades do sul do país, foram selecionados a partir de três marcadores sociais da diferença (orientação sexual, cor de pele e deficiência física) para a participação em um grupo focal, com duração de $1 \mathrm{~h}$ e $30 \mathrm{~min}$. Três eixos analíticos foram explorados: 1) representações de masculinidades; 2) invisibilidade e sua relação com o modelo dominante de masculinidade; 3) visibilidade e sua relação com privilégios das masculinidades. A análise construtivo-interpretativa permitiu explorar zonas de sentido sobre a produção de diferenças em torno de um eixo naturalizado, que por sua vez produz opressões contra as quais os sujeitos reagem de diferentes formas. Compreendeu-se que o indivíduo não ocupa um lugar fixo de "opressor" ou "oprimido", mas que essas instâncias se dão de forma contextual, localizada e intercambiável.
\end{abstract}

Palavras-chave: Identidade de gênero; masculinidade; preconceito.

\section{Abstract}

This study is an investigation on the production of subjective meanings related to male gender identity. Four cisgender men $(26,31,32$, and 37 years old) from the south of Brazil were selected according to social markers of difference (sexual orientation, skin color and physical disability) to take part in a focus group, which lasted for 1 and a half hour. Three analytical axes were explored: 1) representations on masculinities; 2) invisibility and its relation to the dominant model of masculinity; 3) visibility and its relation to masculinity privileges. The constructive-interpretative analysis allowed exploring meaning zones produced around a naturalized axis that elicits oppressions against which subjects react in different ways. We considered that the individual does not remain in a fixed position of "oppressor" or "oppressed", because these instances take place in a contextual, located and interchangeable manner.

Keywords: Gender identity; masculinity; prejudice.

* Psicólogo pela Faculdade Meridional IMED (2014). Mestre e Doutorando em Psicologia pela Universidade do Vale do Rio dos Sinos. Bolsista CAPES/ PROSUP. Professor do Curso de Psicologia da Faculdade Meridional IMED.

** Licenciado em História pela Universidade de Passo Fundo (2005). Mestre em História Regional, pela Universidade de Passo Fundo (2013 - 2015). Atua principalmente nos seguintes temas: gênero e história, história da sexualidade, identidades, combate às opressões interseccionais na escola e nos espaços públicos.

*** Possui graduação e especialização em Psicologia pela Universidade de Passo Fundo (1999/2001); Mestrado em Psicologia Social e da Personalidade pela PUCRGS (2003); Doutorado em Psicologia Clínica pela PUCRGS (2016). Prof. da Pós-graduação em Dinâmicas das Relações Conjugais e Familiares.

**** Possui graduação em Psicologia pela PUCRG do Sul (1988); Especialização em Psicoterapia Psicanalítica CELG/UFRGS; Mestrado e Doutorado em Linguística e Letras pela PUCRGS (1996/1999). Professora Associada-I do curso de Psicologia da Universidade Federal de Santa Maria e da Pós-Graduação em Psicologia da UFSM. 


\section{Introdução}

Homem não chora, não demonstra sentimentos, não é mulher, não é homossexual, não ama mulheres da forma que mulheres amam homens, não é fraco, não é covarde, não é perdedor e não é passivo nas relações sexuais. Essas e outras representações de masculinidade têm sido investigadas pelos estudos de gênero como integrantes de um processo de naturalização (Silva, 2006). A aparente naturalidade dessas características advém da repetição estilizada de modelos construídos de identidade, que se configuram como uma conquista performativa (Butler, 1988). Nesse sentido, uma questão importante para as pesquisas em gênero é desfazer a relação direta entre homens e masculinidades versus mulheres e feminilidades, fazendo uso da produção teórica feminista, buscando outras posições ontológicas e epistemológicas para além da ordem de gênero binária e normativa (Gottzén \& Mellström, 2014).

Identidade de gênero se refere à relação que as pessoas estabelecem com o sistema cultural de sexo-gênero de sua sociedade (American Psychological Association [APA], 2011). Independentemente de características anátomo-fisiológicas ou orientações sexuais, as pessoas vivenciam o gênero de forma binária (masculino ou feminino), ou não binária, neste caso, não desejam ser reconhecidas especificamente como homens ou mulheres (APA, 2011; Jesus, 2012; Sennott \& Smith, 2011). É errôneo supor que identidade de gênero seja referência obrigatória da sexualidade (Butler, 2004), pois a orientação sexual se refere à atração física, romântica e/ou emocional que uma pessoa sente por outra (APA, 2011).

Em se tratando de representações culturais, o gênero masculino é frequentemente associado ao não cuidado de si (Nascimento, Trindade, Gianordoli-Nascimento, Pereira, Silva, \& Cerello, 2011). Isso pode ser explicado pelo fato de que homens geralmente respondem a um ideal de masculinidade que se reflete na não valorização de sua saúde (Mendonça, Menandro, \& Trindade, 2011). Por exemplo, entre meninos adolescentes, a presença de doenças sexualmente transmissíveis está associada às representações sociais da masculinidade (Arraes et al., 2013). Ao circularem pela cultura, essas crenças e pressupostos produzem as próprias classificações que autorizam homens a discriminar, subordinar, marginalizar ou excluir outros homens no curso das interações sociais (Silva \& Guerra, 2012).

O conceito de masculinidade hegemônica auxilia na compreensão da dinâmica das hierarquias que se estabelecem entre diferentes formas de masculinidade, quando se toma um modelo único do que é ser homem em detrimento de quaisquer outras vivências subjetivas da identidade de gênero masculina (Connel \& Messerschmidt, 2013). Para responder, por exemplo, se violência é coisa de homem, é preciso investigar em que medida o modelo hegemônico de masculinidade influencia o sujeito que pratica violência (Nascimento, Gomes, \& Rebello, 2009).

Algumas pesquisas em criminologia entendem que homens não cometeriam crimes pelo fato de serem homens, mas para atingir os ideais da masculinidade hegemônica (Bufkin, 1999; Messerschmidt, 1997). Uma análise de 28 casos de atiradores adolescentes em escolas americanas (de 1982 a 2001) mostrou que a maioria dos meninos atiradores haviam sofrido bullying sistemático cujo conteúdo era a homofobia, percebida como uma ameaça à masculinidade (Kimmel \& Mahler, 2003). Um dos sistemas de crença que sustenta o modelo de masculinidade hegemônica é o heterocentrismo. Segundo Jesus (2013), trata-se de um conjunto de crenças que classifica e organiza a sexualidade da sociedade, baseando-se no pressuposto de que a heterossexualidade (reprodutiva, marital e monogâmica) seja natural, constituindo uma forma de organização de pensamento que gera práticas de invisibilização, estigmatização, discriminação e violência.

O gênero é atravessado por outros marcadores sociais da diferença, além da orientação sexual, como classe, cor/raça, etnia, geração, "deficiência" (o termo será problematizado mais adiante), entre outros. As discussões sobre marcadores sociais da diferença iniciaram a partir da autocrítica do movimento feminista norte-americano, ao longo dos anos 1980, questionando a representação de mulher associada à cor/raça branca, à heterossexualidade e à classe média (Pelúcio, 2011). Esses marcadores se tornam visíveis ou passam a importar dependendo da instituição, grupo ou contexto no qual os sujeitos se encontrem (Souza, 2006). Marcadores sociais da diferença são derivações "que se enfeixam de maneira que o eixo de diferenciação constitui o outro ao mesmo tempo em que é constituído pelos demais" (Pelúcio, 2011, p. 79). Para evitar o reducionismo de pensar em um único eixo como gerador de todas as diferenças, deve-se analisar a interseccionalidade das opressões, ou seja, como elas se inter-relacionam nos diferentes contextos (Facchini, 2009).

Ainda não é claro e visível para a sociedade que a produção de uma anormalidade é a produção de uma diferença do que se considera normal: quando certas normas de vida são compartilhadas pela maioria, elas passam a significar uma normatividade vital e também 
uma normatividade social, que passam a se igualar (Safatle, 2011). Aquilo que se designa como anormal é a manifestação de outras possibilidades de vida, que por serem consideradas inferiores, recebem a nominação de patológicas: "sua normalidade advirá de sua normatividade" (Canguilhem, 2002, p. 113).

\section{Subjetividade}

O estudo da subjetividade foi capaz de traduzir a noção da complexidade de Morin para o campo da Psicologia (Scoz, 2008), portanto, a subjetividade não pode ser reduzida à simplificação (González Rey, 2005). A subjetividade não é um sinônimo do que comumente se entende como "o psicológico", mas uma nova categoria ontológica que rompe com a dicotomia individual-social e fornece outra forma de compreensão teórica (González Rey, 2005, 2011a, 2012a). Subjetividade é a "organização dos processos de sentido e de significação que aparecem e se organizam de diferentes formas e em diferentes níveis no sujeito e na personalidade, assim como nos diferentes espaços sociais em que o sujeito atua" (González Rey, 1999, p. 108).

Para compreender o estudo da subjetividade nesta perspectiva, é preciso esclarecer dois conceitos: sentido subjetivo e configuração subjetiva. O sentido subjetivo é a unidade inseparável de símbolos e emoções, sendo que um evoca o outro, mas não o determina (González Rey, 2002 , 2003). O sentido subjetivo é a unidade integradora de diversos elementos da cultura e da realidade social, mas pode ser produzido apenas em momentos da vida do sujeito (González Rey, 2006, 2012a).

Já as configurações subjetivas representam formas mais estáveis de organização de sentidos subjetivos (González Rey, 2012a). A configuração subjetiva é a "complexa rede de sentidos subjetivos organizados em relação a um tema ou ação humana" (González Rey, 2006, p. 74). O tema da subjetividade tem sido negado pelas correntes pós-positivistas e estruturalistas, pois oferece outras representações da organização da psique humana, exigindo das pesquisas em Psicologia a não-subordinação às representações sociais hegemônicas (González Rey, 2011a).

Frente ao exposto, nesta pesquisa, buscou-se investigar sentidos subjetivos produzidos em relação à identidade de gênero masculina, articulando pontos de vista a partir de marcadores sociais da diferença. Ao problematizar representações compartilhadas sobre a masculinidade, intencionou-se explorar percepções de sujeitos em relação ao discurso do modelo hegemônico e percepções de privilégios sociais em relação às mulheres.

\section{Método}

Trata-se de uma pesquisa de delineamento exploratório baseada na Epistemologia Qualitativa de González Rey (1997, 2005, 2011a, 2011b, 2012a), uma proposta para o estudo científico da subjetividade. A lógica configuracional utilizada pelo autor fornece uma alternativa à lógica da resposta - dicotomia teoria versus empírico, onde o último confirmaria a legitimidade da construção do primeiro (González Rey, 2012a). Os instrumentos são utilizados como recursos geradores de dinâmicas conversacionais para que participantes expressem sentidos produzidos no momento da pesquisa (González Rey, 2012a). As informações produzidas seguem a análise de conteúdo construtivo-interpretativa, uma forma de construir "modelos teóricos compreensivos e com valor explicativo sobre sistemas complexos cuja organização sistêmica é inacessível à observação" (González Rey, 2012a, p. 89). Durante a análise, os indicadores (González Rey, 2011a, 2012a) são elementos iniciais que dão sentido a uma construção teórica - não autorizam conclusões, mas permitem a articulação de hipóteses que dão visibilidade a processos aparentemente invisíveis.

\section{Participantes}

Optou-se por amostragem não probabilística, seguindo o critério de conveniência, para explorar a diversidade em detrimento da representatividade dos dados (Barbour, 2009). Um anúncio publicado em redes sociais e enviado por e-mail convidou pessoas de identidade de gênero masculina, independentemente de orientações sexuais, características corporais, documentos de registro e/ou reconhecimento social. Quatro homens (idades 26, 31, 32 e 37 anos) residentes e nascidos em cidades do Rio Grande do Sul responderam ao anúncio e se disponibilizaram a participar de um grupo focal. Optou-se pelo mínimo de pessoas necessárias para a formação de um grupo focal (de 4 a 8), segundo Barbour (2009).

\section{Instrumentos e Procedimentos}

Foi realizado um grupo focal (Barbour, 2009) em uma clínica-escola do Rio Grande do Sul. Nesta técnica, um/a facilitador/a trabalha para estimular a interação grupal a partir de um guia de tópicos, permitindo o aprofundamento de percepções em torno de um tema, tornando o grupo focal uma estratégia eficaz para encontrar lógicas plausíveis em ideias aparentemente ilógicas (Barbour, 2009) e para entender o porquê das pessoas pensarem de determinadas formas (Morgan, 1996). O guia de tópicos foi desenvolvido a partir dos objetivos específicos da 
pesquisa, organizados em três eixos investigativos: 1) representações de masculinidade; 2) invisibilidade e modelo dominante de masculinidade; 3) visibilidade e privilégios das masculinidades. O grupo focal teve duração de $1 \mathrm{~h} \mathrm{e}$ $30 \mathrm{~min}$. O Termo de Consentimento Livre e Esclarecido foi lido em voz alta, discutido e posteriormente assinado pelos participantes. A atividade foi gravada em áudio e posteriormente transcrita; dados de identificação foram anonimizados na transcrição. Esta pesquisa respeitou a Resolução 466/2012, do Conselho Nacional de Saúde e foi aprovada pelo Comitê de Ética em Pesquisa da Faculdade Meridional (IMED), sob o número 782.888.

\section{Análise das informações}

A partir das três categorias de investigação do guia de tópicos do grupo focal, foram levantados indicadores de sentidos subjetivos que estimulavam o desenvolvimento de modelos teóricos compreensivos sobre "zonas de sentido", ou seja, "espaços de inteligibilidade que se produzem na pesquisa científica e não esgotam a questão que significam" (González Rey, 2012a, p. 6). Os recortes arbitrários permitiram a produção de informação, aqui entendida não como expressão direta dos dados coletados, mas como processo interpretativo que incluiu o pesquisador como sujeito produtor de um saber na produção deste saber (González Rey, 2011a, 2012a). O uso reflexivo dos possíveis impactos de pesquisadores/ as nos dados garante "vantagem analítica" (Barbour, 2009 , p. 78), e é justamente essa relação que permite a produção de um conhecimento cuja legitimidade não se aplica à perspectiva de replicabilidade ou generalização, mas se associa às zonas de sentido que progressivamente desenvolvem o problema estudado e "à forma com que as novas categorias se articulam para aumentar a capacidade heurística do modelo diante dos desafios que aparecem na pesquisa" (González Rey, 2012a, p. 112).

\section{Resultados e discussão}

\section{Marcadores sociais da diferença}

Para facilitar a compreensão dos sentidos produzidos nas interações, nomes fictícios foram criados para apresentar os participantes em relação aos três marcadores sociais da diferença investigados neste estudo: Bruno (26), funcionário público, e Thiago (32), designer, são socialmente marcados pela orientação sexual diferente da heterossexual; Felipe (31), médico, é marcado pela cor da pele não branca; e Leonardo (37), professor, traz em seu corpo o marcador da pessoa com deficiência. Somente um marcador foi atribuído a cada participante: Felipe e Leonardo apresentaram-se como heterossexuais; Leonardo, Bruno e Thiago são brancos; Bruno, Thiago e Felipe caminham sem o uso de cadeira de rodas.

No diálogo transcrito, foram identificadas palavras que representassem os marcadores sociais da diferença mencionados acima (número de repetições entre parênteses): "gay" (31), "viado" (5) e "homossexual" (4) referiram-se a uma orientação sexual marcada - não heterossexual; "negro" (9), "negão" (3) e "preto" (2) referiram-se à cor de pele marcada - não branca; "cadeirante" (4), "homem de cadeira de rodas" (1), "deficiente" (1) e "aleijado" (1) referiram-se a uma pessoa com deficiência física. Ao descrevermos alguém, também estamos produzindo alguém, ou seja, formando os sujeitos dos quais estamos falando (Foucault, 2008). Essa ressalva serve de alerta para que os participantes desta pesquisa não sejam tipificados ("um gay", "um negro", "um cadeirante") ou suas falas reduzidas a um único lugar de enunciação ("O gay", "o negro", "o cadeirante”), mas que sejam considerados como sujeitos cujos processos de subjetivação são atravessados pelos marcadores socialmente atribuídos e subjetivamente autoatribuídos.

As palavras "gay", "viado", "homossexual", "negro", "negão", "preto", "cadeirante", "deficiente" e "aleijado" têm seu uso variado, por exemplo, pela escolha gramatical: podem ser utilizadas ao mesmo tempo como adjetivos, qualificando ou desqualificando sujeitos, ou como substantivos, nomeando-os. Esta variação também depende do contexto em que as palavras são utilizadas, pois podem servir à intenção de agredir ou discriminar, como também podem marcar processos de fortalecimento mútuo de identidades/subjetividades sociais e conquista de direitos civis. Relevante notar que as palavras que nomeiam o "neutro", quando elas existem, nunca ou raramente são utilizadas como xingamento (heterossexual, branco, "caminhante") e, ainda que o fossem, não trariam grandes prejuízos ao sujeito que encontra no sistema social o reconhecimento de sua não diferença.

Embora a comunicação aconteça a partir do compartilhamento de representações sociais que se mantêm relativamente estáveis ao longo do tempo (Moscovici, 2013), os sentidos subjetivos são produzidos na relação do sujeito com essas representações, em determinado espaço, em determinado tempo (González Rey, 2012b). Assim, para investigar representações de masculinidade entre os participantes, foi utilizado o disparador: "Para você, o que é ser homem? ”. 
Imediatamente, Bruno lançou a primeira frase, em tom jocoso: "ser homem é ter um tico [pênis] no meio nas pernas". Os risos descontraídos que se seguiram à brincadeira de Bruno possivelmente teriam causado desconforto se no grupo estivesse presente um homem não cisgênero. Este termo é um contraponto a "transgênero", com o objetivo de denunciar a naturalização de um sistema sexo/gênero marcado em termos como "não transgênero", "homem biológico", ou "mulher biológica". Se o gênero de algumas pessoas recebe o prefixo trans (do outro lado), então é justo nomear o gênero cis (do mesmo lado), pois são ambas construções socioculturais (Aultman, 2014; Jesus, 2012, 2013; Schilt \& Westbrook, 2009). As pessoas cis possuem, desde o nascimento e ao longo de sua vida, os órgãos sexuais reprodutivos masculinos ou femininos associados ao construto "homem" ou "mulher" (identidade de gênero), ou seja, a pessoa está "do mesmo lado" em termos da normativa sexo-gênero (Aultman, 2014). Pessoas trans foram classificadas nos catálogos médicos e documentos referenciais "como portadoras de um conjunto de indicadores comuns que as posicionam como transtornadas, independentemente das variáveis históricas, culturais, sociais e econômicas" (Bento \& Pelúcio, 2012, p. 572). Atualmente, a terminologia encontrada no Manual Diagnóstico e Estatístico de Transtornos Mentais (DSM-5) é "disforia de gênero" (American Psychiatric Association, 2013). Já na Classificação Estatística Internacional de Doenças e Problemas Relacionados com a Saúde (CID), o termo que tem sido discutido para inclusão na próxima versão (CID-10) é "incongruência de gênero" (Beek, Cohen-Kettenis, Bouman, Vries, Steensma, Witcomb, Arcelus, Richards, Elaut, \& Kreukels, 2016). De fato, para muitos homens trans, não é preciso ter nascido com um pênis, nem sequer possuir o desejo de tê-lo, para conquistar o direito de serem reconhecidos socialmente como homens (Almeida, 2012; Ávila, 2014), ou seja, masculinidade não é necessariamente coisa de homem nem se reduz ao corpo assignado como masculino (Halberstam, 1998).

Felipe menciona que ser homem "até é ter um pênis”, mas que não se deve dar importância para isso; segundo ele, homem é "aquele que protege, que é cavalheiro". De fato, existe uma multiplicidade de saberes que se articulam na manutenção do sistema binário pênis-macho-homem-masculino versus vagina-fêmea-mulher-feminino (Bento \& Pelúcio, 2012), incluindo as representações associadas ao cavalheirismo e à proteção que, se entendidos como naturais, reificam o modelo essencialista da diferenciação sexual. Já Thiago e Leonardo se referiram ao homem como "ser humano" e ambos concordaram que o gênero seria uma limitação, por determinar papéis e regras sociais. O que pode não estar evidente na conversa é a noção de homem como sujeito universal, como sujeito por excelência (Bourdieu, 2014), resultado de um processo histórico de naturalização que envolve o esquecimento das origens de sua construção (Moscovici, 2013).

\section{Negociações de Masculinidades}

Os quatro participantes manifestaram uma percepção semelhante da sociedade, como preconceituosa e excludente. Felipe opina: "não basta perceber que a sociedade é preconceituosa e ficarmos quietos". Para ele, a mudança deve começar "em casa", impedindo a reprodução de valores com os quais não concordamos. Esta ideia de Felipe, corroborada por outras ao longo diálogo, ilustra a percepção de que nosso conhecimento também é uma instituição: "nossas representações são também instituições que nós partilhamos e que existem antes de nós termos nascido dentro delas; nós formamos novas representações a partir das anteriores ou contra elas" (Moscovici, 2013, p. 318).

As orientações sexuais marcadas são aquelas que diferem da heterossexualidade. Thiago e Bruno apresentaram diferentes sentidos em relação a este marcador. Thiago percebe que os espaços sociais exigem uma constante explicação do diferente: "eu não preciso seguir o padrão [...] mas eu tenho que estar afirmando isso o tempo todo, infelizmente". Em resposta, Bruno foi incisivo: "tô cagando e andando", mas comentou em seguida que até "dá uma de macho" ou tenta "ser menos viado" em determinados espaços, principalmente no âmbito profissional. Ao mesmo tempo em que Bruno declara desprezo em relação às normativas, parece corroborá-las em determinados contextos. Thiago discordou que Bruno devesse "ser menos viado" em qualquer situação: "isso é uma sacanagem!". Somente o sujeito pode decidir pelos caminhos de suas ações nos espaços pelos quais circula, e cada decisão envolve a produção de novas rotas de sentidos (González Rey, 2012b). Thiago parece expressar mais incômodo do que desprezo, pois nota-se que não segue um padrão, mas sente que precisa afirmar-se no mesmo lugar de humanidade garantido aos sujeitos por excelência (os ideais do eixo "neutro").

Felipe nasceu na capital e hoje mora no interior, em uma cidade de colonização italiana. Contou que havia ponderado se sofreria ainda mais preconceito racial do que em uma cidade grande, e hoje sente-se dividido: 
"por um lado eu fiquei feliz, mas descontente e com um pouco de raiva por outro, porque a sociedade me aceitou muito bem pela posição social". Relatou que sempre fora o único negro em sala de aula e que aprendeu com o avô a driblar o preconceito com inteligência, sempre buscando o primeiro lugar. Bruno passou em concursos públicos em excelentes colocações e tornou-se presidente de uma associação. O comentário subsequente de Thiago trouxe a noção do "trabalho dobrado", quando o sujeito marcado conquista o respeito e reconhecimento social que parecem automaticamente garantidos aos sujeitos que atendam ou se assemelhem aos ideais normativos, mas não com os mesmos esforços e muito menos com as mesmas oportunidades.

Cada participante se relaciona de maneira única com normas sociais que percebem como excludentes. A conformidade em relação às normas masculinas está associada a um baixo bem-estar psicológico e à rigidez como forma mediadora de relações (Alfred, Hammer, \& Good, 2014). Há duas saídas para o indivíduo: subordinar-se às ordens do que foi institucionalizado ou gerar alternativas singulares (González Rey, 2012b). Os quatro participantes deste estudo desenvolveram estratégias para enfrentar o sistema social de marcadores da diferença, cada qual à sua maneira, a partir das diferentes opressões que eliciaram a necessidade dessas estratégias. O sujeito está sempre imerso em espaços nos quais age e se expressa, em um processo em que desejos são gerados por suas configurações subjetivas, mas também novos desejos são gerados naquele contexto (González Rey, 2012b).

Outra questão levantada foi o estigma da isenção relacionado ao marcador social da pessoa com deficiência. Leonardo afirmou ter ido atrás das responsabilidades as quais sua família havia lhe isentado: "trabalho, educação, mulheres". Único membro da família com ensino superior, Leonardo relatou: "sempre tive que provar quarenta milhões de vezes mais". Ele contou que sua situação se deve às leis de inclusão, e não por reconhecimento, mas que após um ano de trabalho, recebeu uma proposta que o fez perceber que foi reconhecido, não pela lei, mas por si mesmo. O marcador da "deficiência" envolve a isenção dos sujeitos em nome da proteção e do cuidado. Outros marcadores sociais podem não apresentar essa característica, quando, por exemplo, espera-se que uma pessoa trabalhe dobrado para compensar seu marcador social de sexualidade.

Representações sociais servem para possibilitar a comunicação através de uma certa estabilidade de significados: "as crenças têm uma existência antes, durante e depois das existências dos indivíduos singulares" (Moscovici, 2013, p. 287). É justamente na desestabilização de crenças arraigadas, ou de representações hegemônicas, que está uma saída para a transformação de relações de injustiça, conforme ilustra o seguinte trecho de diálogo:

Felipe: Meu sogro é preconceituoso [...] a gente tem trabalhado isso nele, seja em relação à homossexualidade, seja em relação ao negro e ele diz assim, [imita sotaque italiano] 'mas tu tem que ver que a gente é gringo, é a pior raça, e a gente fala sem saber’ [...]

Thiago: Não é em si por maldade...

Felipe: Mas tem que mudar...

Thiago: É!

Felipe: Eu acho que a nossa geração... nós vamos ser agentes de mudança, seja pela lei, seja por mostrar que tu consegue ser o primeiro lugar, [...] na próxima geração já vai ter um mundo um pouco melhor...

\section{Percepções relacionadas: invisibilidade e privilégio}

Uma situação ocorrida durante o grupo focal pode ilustrar um momento de tensão produzido pelo compartilhamento de representações. Quando Leonardo expressou suas ideias em relação ao sexo, disse: "segundo o mito do Platão, o homem e a mulher foram separados, são almas gêmeas que se encontram no cosmo e o ato sexual, o orgasmo, seria a junção de dois seres num só". Nesse momento, Thiago se sentiu incomodado: "eu acho bonito, porém, e quando são dois homens ou duas mulheres?". Leonardo explicou-se, disse que não tinha a intenção de determinar os gêneros, no entanto, sua escolha de palavras despertou em Thiago um "sentimento de invisibilidade". De fato, a comunicação entre as pessoas somente é possível pelo compartilhamento das representações que servem, "por um lado, como paradigmas da comunicação e, por outro lado, como meios de orientação prática” (Moscovici, 2013, p. 356). Mesmo sem esta intenção, a linguagem utilizada por Leonardo não contemplou um lugar para Thiago. A escolha de palavras se dá a partir do vocabulário disponível nas sociedades e (re)apropriado pelos sujeitos, daí a importância da problematização da linguagem e das palavras compartilhadas em uma língua.

Este incômodo "de não ser visto" gerou um segundo momento significativo que permitiu relacionar as percepções que os participantes tinham de invisibilidade e privilégios. Invisibilidade em relação a um modelo de masculinidade hegemônica que anuncia um lugar de legitimidade, e privilégios em relação ao oposto binário do 
gênero masculino - as mulheres. Ressalta-se que esta análise escolheu três marcadores sociais (orientação sexual, cor de pele e deficiência). O marcador social do gênero era neutro (ou não marcado) nos quatro participantes (e no entrevistador), pois o gênero marcado é o feminino. $\mathrm{O}$ gênero masculino é adotado como o "neutro" na linguagem que, conforme dissemos, não apenas descreve, mas produz um sujeito por excelência - o sujeito masculino.

Bruno comentou: "Eu não me vejo no exército brasileiro, por exemplo". Essa frase denuncia as consequências de "ações institucionais de exclusão", que juntamente com a invisibilidade na mídia e na educação, estimulam o esquecimento das particularidades do outro (Jesus, 2013, p. 366). A representação hegemônica de masculinidade associada ao militarismo não contempla determinados sujeitos, ou seja, anuncia o seu não lugar, assim como outros marcadores sociais são uma "novidade" em determinados espaços, conforme a fala de Felipe: "A sociedade [...] tem que frisar que o Barack Obama é o primeiro presidente negro, pra que fazer isso? [...] Se um dia eu for vereador da Cidade $\mathrm{X}$, eu vou ser o primeiro vereador negro da Cidade X". Em seguida, ele olhou para Bruno e disse: "assim como tu seria o primeiro vereador gay da Cidade X”. Marcar um lugar de conquista e superação de estigmas pode, ao mesmo tempo, reificar o eixo estruturante do qual derivam as diferenças. No caso das masculinidades, representações dominantes dependem da subordinação de formas alternativas que se produzem em torno (Halberstam, 1998).

Na produção de subjetividades, a mídia tem um papel fundamental. Leonardo relatou que não vê homens de cadeira de rodas em novelas. Para Bruno e Thiago, os gays podem estar na novela, mas não representam todos os gays. Felipe diz que os negros das novelas são muito poucos e geralmente recebem o papel de empregados. Em razão da preocupação com a audiência, a mídia privilegia uma espécie de consenso capaz de atingir camadas médias e populares da sociedade, não sendo capaz de perceber todas as tendências (Almeida, 2013). É esse "ficar de fora" que produz a sensação de invisibilidade e que, ao mesmo tempo, sustenta as fronteiras do "dentro". Ao mencionar a ausência de super-heróis negros, Felipe denuncia o que está escondido: a representação que associa heroísmo a uma cor de pele não marcada.

O único momento de silêncio durante toda a atividade apareceu a partir do disparador que o pesquisador utilizou para investigar a percepção de privilégios sociais: "Em algum lugar na sua vida, ou nos seus espaços sociais, você sente que tem alguma espécie de privilégio por ser homem?”. A percepção de injustiça é bastante clara, mas a percepção de privilégios parece atrapalhada por "pontos cegos" e generalizada, despersonalizada, como ilustra a fala de Thiago, que não lembrou de um exemplo específico: "eu vejo que os homens têm um privilégio no geral, tem mais vagas pra homem, mais programas de TV pra homem, me parece que os homens, a cultura toda, a sociedade toda tem um privilégio maior pra homens do que pras mulheres". Para lembrar-se, é preciso ter-se dado conta, ou seja, é preciso ter tido a percepção privilégio, o que nos escapa por pontos cegos em relação a um eixo estrutural. Thiago mencionou que "os melhores cargos são pra homens, os melhores salários são pra homens". Uma hipótese sobre a disparidade salarial é que esse modelo econômico esteja a serviço da manutenção de um modelo familiar que teme que a mulher, caso tenha mais poder de decisão, deixará de realizar tarefas tradicionalmente assignadas a seu gênero (Madalozzo, Martins, \& Shiratori, 2010).

Somente após alguns minutos, os homens do grupo passaram a relatar experiências de privilégio em relação às mulheres que efetivamente envolvessem suas vidas $\mathrm{e}$ a observação de seus próprios espaços e relações sociais. Um exemplo que melhor ilustra a percepção do sujeito de seus privilégios sociais é o de Felipe. Ele conta que é o único homem em sua unidade de saúde e acaba sempre coordenando as reuniões, mesmo não querendo: "eu sempre procurei fazer com que não existisse um coordenador só e que todo mundo possa pegar junto, mas centralizam isso em mim e acaba que eu assumo esse papel". Felipe parece tentar subverter os marcadores sociais que acabam por legitimar o homem como o sujeito com a "palavra final", mas percebe-se sem apoio das colegas. Bruno cita um exemplo semelhante: "lá na Cidade X, no posto de saúde, também só tem um homem, e ele é o que coordena". Por ser o machismo um problema estrutural, a discussão feminista necessita adentrar em todos os espaços, questionando as normas de gênero que subjetivam os sujeitos e que são mantidas por eles, em reproduções inconscientes ou deliberadas.

Bruno citou o exemplo de uma empresa de sua cidade. "Eles querem menino para trabalhar na parte que indica os filmes [para os clientes], mas o menino tem que ser gay... [...] As meninas que eles contratam ali é só pra [...] cozinha". Felipe indagou: "Por que será?” Bruno respondeu: "Sei lá... [...] gays se comunicam mais... são mais comunicativos". Nota-se, nesta fala, uma intersecção de estereótipos: mulheres associadas à cozinha, homens associados à intelectualidade, gays associados à comunica- 
ção e alegria. Há um jogo de representações que antecede a pessoa, que vem antes do nome do sujeito e de sua subjetividade e que perdura para além dele.

\section{Considerações finais}

Configurações subjetivas da identidade de gênero masculina são produzidas no compartilhamento de representações sociais de masculinidades, cuja normativa "invisível" se estabelece na noção de masculinidade hegemônica. Marcadores sociais surgem por derivação de um pressuposto neutro, um eixo estrutural naturalizado ao longo da história e, portanto, sem nome. A partir dele são produzidas as diferenças, que vão se reproduzindo horizontalmente (p. ex., gays e lésbicas que discriminam pessoas trans). O que deriva do eixo acaba tendo um estatuto próprio (da mulher, da criança, do idoso, da diversidade sexual etc.).

Os participantes se percebem em um lugar de legitimidade não garantida automaticamente, devido aos marcadores sociais que os identificam (orientação sexual, cor de pele e deficiência). As estratégias de cada sujeito em relação ao seu lugar marcado são diversas e variadas; cada uma delas pode indicar, ao mesmo tempo, uma conquista em relação à superação da opressão e uma reificação do eixo que a produziu. A percepção de privilégios permite a analogia com a percepção de invisibilidade em relação a um modelo hegemônico, ou seja, ao mesmo tempo em que o sujeito percebe que exclui, percebe que é excluído pela mesma razão: a produção de diferença. O sujeito pode, então, sofrer discriminação e discriminar ao mesmo tempo. A percepção dos próprios privilégios sociais pode ser um caminho para impedir a reprodução de discriminação, pois permite identificar redes e intersecções de opressão, que devido à naturalização, não são facilmente percebidas.

Com as limitações deste estudo, procuramos explorar o caminho da desnaturalização do gênero, colocando em questão os discursos dominantes que produzem e reproduzem a violência de gênero e o heterocentrismo estrutural. Assim, é preciso continuar compreendendo como os marcadores sociais se sobrepõem nas intersecções de opressões e como a percepção de privilégios, através da emergência do sujeito, pode abrir caminhos para relações mais justas, menos entre homens e mulheres, e mais entre pessoas.

\section{Referências}

Alfred, G. C., Hammer, J. H., \& Good, G. E. (2014). Male student veterans: Hardiness, psychological well-being, and masculine norms. Psychology of Men \& Masculinity, 15(1), 95-99.
Almeida, G. de. (2012). Homens trans: Novos matizes na aquarela das masculinidades? Revista Estudos Feministas, 20(2), 513-523.

Almeida, H. B. de. (2013). Identificações afetivas: Telenovela e as interpretações das audiências. Runa, 34(2), 163-176.

American Psychiatric Association. (2013). Diagnostic and statistical manual of mental disorders (5th ed.). Washington, DC: Author.

American Psychological Association. (2011). Answers to your questions: About transgender people, gender identity, and gender expression. Washington, USA: Public and Member Communications.

Arraes, C. de O., Palos, M. A. P., Barbosa, M. A., Teles, S. A., Souza, M. M. de, \& Matos, M. A. de. (2013). Masculinidade, vulnerabilidade e prevenção relacionadas às doenças sexualmente transmissíveis/HIV/Aids entre adolescentes do sexo masculino: Representações sociais em assentamento da reforma agrária. Revista Latino-Americana de Enfermagem, 21(6), 1273-1273.

Aultman, B. (2014). Cisgender. TSQ: Transgender Studies Quarterly, 1(1-2), 61-62.

Ávila, S. N. (2014). FTM, transhomem, homem trans, homem: A emergência de transmasculinidades no Brasil contemporâneo (Tese de doutorado). Universidade Federal de Santa Catarina, Florianópolis.

Barbour, R. (2009). Grupo focais. (M. F. Duarte, Trad.). (Coleção Pesquisa Qualitativa). Porto Alegre, RS: Artmed.

Bento, B., \& Pelúcio, L. (2012). Despatologização do gênero: A politização das identidades abjetas. Estudos Feministas, 20(2), 559-568.

Bufkin, J. L. (1999). Bias crime as gendered behavior. Social Justice, 26(1), 155-176.

Butler, J. (1988). Performative acts and gender constitution: An essay in phenomenology and feminist theory. Theatre Journal, 40(4), 519-531.

Butler, J. (2004). Undoing gender. Nova York, Estados Unidos: Routledge.

Canguilhem, G. (2002). O normal e o patológico (5a ed.). (M. T. R. C. Barrocas \& L. O. F. B. Leite, Trads.). Rio de Janeiro, RJ: Forense Universitária.

Connell, R. W., \& Messerschmidt, J. W. (2013). Masculinidade hegemônica: Repensando o conceito. Revista Estudos Feministas, 21(1), 241-282.

Facchini, R. (2009). Entre compassos e descompassos: Um olhar para o "campo" e para a "arena" do movimento LGBT brasileiro. Bagoas - Estudos Gays: Gêneros e Sexualidades, 3(4), 131-158.

Foucault, M. (2008). A arqueologia do saber (7a ed.). (L. F. B. Neves, Trad.). Rio de Janeiro, RJ: Forense Universitária.

González Rey, F. L. (1997). Epistemología cualitativa y subjetividade. Havana, Cuba: Pueblo y Educación.

González Rey, F. L. (1999). Psicologia e educação: Desafios e projeções. In O. A. Rays (Ed.), Trabalho pedagógico: Realidades e perspectivas (pp. 102-117). Porto Alegre, RS: Sulina.

González Rey, F. L. (2002). Repenser les fondements épistémologiques de la recherche en psychologie sur les représentations sociales. In C. Garnier \& W. Doise (Eds.), Les representations sociales balisage du domaine d'etudes (pp. 241-264). Montreal, Canadá: Éditions Nouvelles.

González Rey, F. L. (2003). Sujeito e subjetividade. São Paulo, SP: Thompson Pioneira.

González Rey, F. L. (2005). Subjetividade, complexidade e pesquisa em psicologia. São Paulo, SP: Pioneira Thomson Learning.

González Rey, F. L. (2006). As representações sociais como produção subjetiva: Seu impacto na hipertensão e no câncer. Psicologia: Teoria e Prática, $8(2), 69-85$.

González Rey, F. L. (2008). Subjetividad social, sujeto y representaciones sociales. Revista Diversitas - Perspectivas en Psicologia, 4(2), 225-243.

González Rey, F. L. (2011a). Pesquisa qualitativa em psicologia: Caminhos e desafios. (M. A. F. Silva, Trad.). São Paulo, SP: Cengage Learning.

González Rey, F. L. (2011b). Subjetividade e saúde: Superando a clínica da patologia. (Coleção Construindo o Compromisso Social da Psicologia). São Paulo, SP: Cortez.

González Rey, F. L. (2012a). Pesquisa qualitativa e subjetividade: Os processos de construcão da informação. (M. A. F. Silva, Trad.). São Paulo, SP: Cengage Learning.

González Rey, F. L. (2012b). O social na psicologia e a psicologia social: a emergência do sujeito (3a ed.) (V. L. M. Joscelyne, Trad.). Petrópolis, RJ: Vozes.

Gottzén, L., \& Mellström, U. (2014). Changing and globalising masculinity studies. NORMA: International Journal for Masculinity Studies, 9(1), 1-4.

Halberstam, J. (1998). Female masculinity: Masculinity without men. Durham, Estados Unidos: Duke University Press. 
Jesus, J. G. (2012). Orientações sobre identidade de gênero: Conceitos e termos (2a ed.) (rev. amp.). Disponível em http://www.sertao.ufg.br/pages/42117-orientacoes-sobre-identidade-de-genero-conceitos-e-termos

Jesus, J. G. (2013). O conceito de heterocentrismo: Um conjunto de crenças enviesadas e sua permanência. Psico-USF, 18(3), 363-372.

Kimmel, M. S., \& Mahler, M. (2003). Adolescent masculinity, homophobia, and violence: Random school shootings, 1982-2001. American Behavioral Scientist, 46(10), 1439-1458.

Madalozzo, R., Martins, S. R., \& Shiratori, L. (2010). Participação no mercado de trabalho e no trabalho doméstico: Homens e mulheres têm condições iguais? Revista Estudos Feministas, 18(2), 547-566.

Mendonça, V. S., Menandro, M. C. S., \& Trindade, Z. A. (2011). Entre o fazer e o falar dos homens: Representações e práticas sociais de saúde. Revista de Estudios Sociales, (38), 155-164.

Messerschmidt, J. W. (1997). Crime as structured action: Gender, race, class and crime in the making. Thousand Oaks, Estados Unidos: Sage.

Morgan, D. (1996). Focus groups as qualitative research (2nd ed.). (Series Qualitative Research Methods, Vol. 16). Thousand Oaks, Estados Unidos: SAGE Publications.

Moscovici, S. (2013). Representações sociais: Investigações em psicologia social (10a ed.). (P. A. Guareschi, Trad.). Petrópolis, RJ: Vozes.

Nascimento, A. R. A. do, Trindade, Z. A., Gianordoli-Nascimento, I. F., Pereira, F. B., Silva, S. A. T. da C., \& Cerello, A. C. (2011). Masculinidades e práticas de saúde na região metropolitana de Belo Horizonte - MG. Saúde e Sociedade, 20(1), 182-194.
Nascimento, E. F. do, Gomes, R., \& Rebello, L. E. F. de S. (2009). Violência é coisa de homem? A naturalização da violência nas falas de homens jovens. Ciência \& Saúde Coletiva, 14(4), 1151-1157.

Pelúcio, L. (2011). Marcadores sociais da diferença nas experiências travestis de enfrentamento à aids. Saúde e Sociedade, 20(1), 76-85.

Safatle, V. (2011). O que é uma normatividade vital? Saúde e doença a partir de Georges Canguilhem. Scientiae Studia, 9(1), 11-27.

Schilt, K., \& Westbrook, L. (2009). Doing gender, doing heteronormativity: "Gender normals", transgender people, and the social maintenance of heterosexuality. Gender \& Society, 23(4), 440-464.

Scoz, B. J. L. (2008). Subjetividade de professoras/es: Sentidos do aprender e do ensinar. Psicologia da Educação, (26), 5-27.

Sennott, S., \& Smith, T. (2011). Translating the sex and gender continuums in mental health: A transfeminist approach to client and clinician fears. Journal of Gay \& Lesbian Mental Health, 15(2), 218-234.

Silva, D. Q. da, \& Guerra, O. U. (2012). Masculinidades en Cuba: Legitimación de una dimensión de los estudios de género. Revista de Estudios Sociales, (42), 93-103.

Silva, S. G. da. (2006). A crise da masculinidade: Uma crítica à identidade de gênero e à literatura masculinista. Psicologia Ciência e Profissão, 26(1), 118-131.

Souza, E. R. de. (2006). Marcadores sociais da diferença e infância: Relações de poder no contexto escolar. Cadernos Pagu, 26, 169-199.

Submetido em: 2-12-2016

Aceito em: 24-4-2017 